\title{
Continuous supercritical synthesis and dielectric behaviour of the whole BST solid solution
}

\author{
H Reverón, C Elissalde, C Aymonier, C Bousquet, M Maglione and \\ F Cansell
}

Institut de Chimie de la Matière Condensée de Bordeaux (ICMCB), CNRS-UPR 9048, Bordeaux I University; 87, avenue du Dr Schweitzer, 33608 PESSAC Cedex, France

E-mail: cansell@icmcb-bordeaux.cnrs.fr

\begin{abstract}
In this study we show that pure and well crystallized nanoparticles of $\mathrm{Ba}_{x} \mathrm{Sr}_{1-x} \mathrm{TiO}_{3}(\mathrm{BST})$ can be synthesized over the entire range of composition through the hydrolysis and further crystallization of alkoxide precursors under supercritical conditions. To our knowledge, this is the first time that the whole ferroelectric solid solution has been produced in a continuous way, using the same experimental conditions. The composition of the powder can be easily controlled by adjusting the feed solution composition. The powders consist of soft-aggregated monocrystalline nanoparticles with an average particle size ranging from $\sim 20$ to $40 \mathrm{~nm}$. Ferroelectric ceramics with accurately adjustable Curie temperature (100-390 K) can thus be obtained by sintering.
\end{abstract}

\section{Introduction}

Ceramic materials and single crystals exhibiting ferroelectric behaviour have been used for years in many electronic and optical applications. In particular, over the last five decades, barium titanate ceramics $\left(\mathrm{BaTiO}_{3}\right)$ were extensively studied because of their high dielectric permittivity and good thermal stability, which have allowed their use in the composition of several devices such as for example in multilayer ceramic capacitors (MLCCs) [1-3]. At room temperature, barium titanate ceramics with micrometre-scale grains exhibit a ferroelectric behaviour (tetragonal phase) which disappears at a Curie temperature of $T_{\mathrm{c}}=120^{\circ} \mathrm{C}$ (cubic phase) [4]. When the size of the grains decreases, it has been shown that the centrosymmetric cubic phase can be stabilized at lower temperatures. This decrease of $T_{\mathrm{c}}$ is referred to as the grain-size effect [5]. Therefore, as the grain size of $\mathrm{BaTiO}_{3}$ plays a major role in ferroelectric properties, much attention has been paid to the synthesis of single-phase $\mathrm{BaTiO}_{3}$ ceramics with a controlled microstructure (grain size $>$ critical size) [6]. In addition, chemical considerations such as both stoichiometry and composition control are also important parameters for the control of the ferroelectric properties. For example, in the system $\mathrm{BaTiO}_{3}-\mathrm{SrTiO}_{3}$ the high $T_{\mathrm{c}}$ value of pure $\mathrm{BaTiO}_{3}$ ceramics can be decreased by increasing the $\mathrm{Sr}$ content and the dependence of the permittivity on the electric field can be accurately tailored (tunability) [7-9]. The barium strontium titanate solid solutions $\left(\mathrm{Ba}_{x} \mathrm{Sr}_{1-x} \mathrm{TiO}_{3}\right.$ or BST) are then very attractive for tunable resonators, filters, phase-shifters, variable-powder dividers and variablefrequency oscillators $[10,11]$.

The current tendency towards the miniaturization of electronic components requires the production of nanoparticles with a particle size typically less than $100 \mathrm{~nm}$. The conventional solid-state route to synthesize BST powders usually leads to the synthesis of powders with a wide particle size distribution in the micrometre range [12-14] containing several secondary phases $\left(\mathrm{Ba}_{2} \mathrm{TiO}_{4}, \mathrm{Ba}_{6} \mathrm{Ti}_{17} \mathrm{O}_{10}\right.$ or $\left.\mathrm{BaTi}_{4} \mathrm{O}_{5}\right)$ or porosity formed during calcination $\left(T>1300{ }^{\circ} \mathrm{C}\right)$ and milling $[15,16]$. In recent years, many researchers have worked on new processes for synthesizing ultra-fine BST particles such as sol-gel [15, 17, 18], precipitation [19-21], hydrothermal [11, 16, 22-24] and mechanochemical [25] methods.

Taking into account the advantages of hydrothermal processing, which lead generally to the production of fine powders at the industrial scale, we have developed a continuous approach to synthesize oxide nanopowders under 
supercritical conditions. Pure and well crystallized BST nanoparticles of controlled composition are demanded in order to enhance the sintering driving force and to obtain well densified ceramics at moderate temperature with adjustable dielectric properties. In this paper we report the synthesis of single-phase $\mathrm{Ba}_{x} \mathrm{Sr}_{1-x} \mathrm{TiO}_{3}$ nanoparticles over the entire solidsolution composition range ( $x=0.0$ to 1.0 ) using a continuous process [26]. The powder characterization and the dielectric behaviour of ceramic are discussed.

\section{Experimental details}

\subsection{Synthesis}

Several feed solutions of precursors with the desired final powder composition $\left(\mathrm{Ba}_{x} \mathrm{Sr}_{1-x} \mathrm{TiO}_{3} ; x=1.0,0.8,0.7,0.6,0.5\right.$, $0.2,0.0$ ) were prepared by dissolving isopropoxides in anhydrous ethanol. The titanium molar composition was $[\mathrm{Ti}]_{\text {prec }}=$ $0.03 \mathrm{~mol}^{-1}$ and the $[\mathrm{Ba}+\mathrm{Sr}]_{\text {prec }}:[\mathrm{Ti}]_{\text {prec }}$ molar ratio was fixed at unity. The synthesis was carried out in a $8 \mathrm{~m}$ tubular coiled reactor (internal volume of $16 \mathrm{~cm}^{3}$ ) fitted with an external heater [26]. The first part of the reactor (from 0 to $4 \mathrm{~m}$ ) was heated at $150{ }^{\circ} \mathrm{C}$ and the last one (from 4 to $8 \mathrm{~m}$ ) at $380^{\circ} \mathrm{C}$. The pressure was fixed at $26 \mathrm{MPa}$ by means of a pressure regulation valve located at the end of the reactor. The facility was highly equipped with flow-meters, temperature controllers and pressure gauges to monitor the process through a computer program. The precursor and pure water were injected into the reactor at $106 \mathrm{~g} \mathrm{~h}^{-1}$ using two high-pressure liquid pumps. The two solutions were mixed at the beginning of the reactor. The BST nanoparticles were recovered in a cell located at the end of the reactor.

\subsection{Characterization}

The powders were characterized by $\mathrm{x}$-ray diffractometry (XRD; model PW 1820, Philips) using $\mathrm{Cu} \mathrm{K} \alpha$ radiation. All compositions were examined over $2 \theta=20^{\circ}-70^{\circ}\left(1.2^{\circ} \mathrm{min}^{-1}\right)$ and $2 \theta=29^{\circ}-35^{\circ}\left(0.04^{\circ} \mathrm{min}^{-1}\right)$ to examine the (110) peak more precisely. Lattice parameters were determined from the (110) peak of single-phase solid solutions. The JCPDS standards used were the following: $\mathrm{BaTiO}_{3}, 75-0461 ; \mathrm{SrTiO}_{3}$, 05-0634; $\mathrm{Ba}_{0.77} \mathrm{Sr}_{0.23} \mathrm{TiO}_{3}, 44-0093 ; \mathrm{Ba}_{0.67} \mathrm{Sr}_{0.33} \mathrm{TiO}_{3}$, 890274; $\mathrm{Ba}_{0.6} \mathrm{Sr}_{0.4} \mathrm{TiO}_{3}, 34-0411 ; \mathrm{Ba}_{0.5} \mathrm{Sr}_{0.5} \mathrm{TiO}_{3}, 39-1395$. The crystallite size was estimated by means of Scherrer's equation assuming that all specimen broadening is due to size effects with negligible non-uniform strain broadening: $D_{\mathrm{XRD}}=$ $0.94 \lambda / B \cos \theta$, where $\lambda$ is the wavelength of $\mathrm{x}$-radiation used $(1.541838 \AA$ for $\mathrm{CuK} \alpha), \theta$ the Bragg angle (110) and $\beta$ the specimen broadening of full width at half maximum intensity $(\mathrm{FWHM})=\left[\beta_{\text {observed }}^{2}-\beta_{\text {instrument }}^{2}\right]^{1 / 2}$, where $\beta_{\text {observed }}=$ FWHM of specimen and $\beta_{\text {instrument }}=$ FWHM contribution from instrument measured with a reference sample (silica) considered to produce negligible specimen broadening. Elemental analysis of products was performed by inductively coupled plasma-atomic emission spectrometry (ICP-AES at the CNRS Central Analysis Service, Vernaison, France). FTIR spectra were obtained using a Perkin-Elmer FTIR spectrophotometer (model Paragon $1000 \mathrm{KBr}$ pellet method). The average particle size ( $\left.D_{\text {TEM }}\right)$ and morphology of BST powders were determined by transmission electron microscopy (TEM, JEOL 2000FX microscope). The mean particle size and its standard deviation were calculated from TEM micrographs by manual counting on populations of at least 300 nanoparticles.

For sintering, the nanopowders with different compositions were uniaxially pressed at $0.5 \mathrm{MPa}$ into discs $(1 \mathrm{~mm}$ in thickness $\times 6 \mathrm{~mm}$ in diameter). The thermal treatment was performed under oxygen atmosphere at $1325^{\circ} \mathrm{C}$ for $4 \mathrm{~h}$ (heating and cooling rates of $100^{\circ} \mathrm{C} \mathrm{h}^{-1}$ ). The microstructure of the sintered compacts was studied using a scanning electron microscope (SEM, JEOL JSM 6360A). Fracture surfaces were preferred over polished surfaces for microstructure observations.

Dielectric measurements were performed on sintered discs using gold as electrode material. The real parts of the permittivity $\left(\varepsilon_{\mathrm{r}}^{\prime}\right)$ derived from the capacitance were measured as a function of temperature (Wayne Kerr 6425 capacitance bridge in a frequency range from 100 to $100000 \mathrm{~Hz}$ ). The Curie temperature $T_{\mathrm{c}}$ was obtained from the thermal variation of $\varepsilon_{\mathrm{r}}^{\prime}$.

\section{Results and discussion}

\subsection{Structural studies of $\mathrm{Ba}_{x} \mathrm{Sr}_{1-x} \mathrm{TiO}_{3}$ solid solutions}

BST powders were processed in the temperature range of $150-380^{\circ} \mathrm{C}$ and at $26 \mathrm{MPa}$ from a mixing of barium, strontium and titanium isopropoxides in ethanol (feed solution). The crystallization of BST nanoparticles $(1.0<x<0.0)$ occurs after the hydrolysis reaction of alkoxides, which takes place at the beginning of the reactor (when water meets the feed solution). Since the reactions of hydrolysis and thermal decomposition are performed at elevated pressure/temperature (solvothermal process), more crystallized structures compared with sol-gel or precipitation methods have been obtained. The synthesis method developed by us allows the control of the BST composition from the composition of the feed solution (precursor). Figure 1 shows the x-ray diffraction (XRD) patterns of the as-synthesized powders. Whatever the composition of the powder, (i) the peaks are identified as pure single phase of $\mathrm{BaTiO}_{3}(x=1.0)$, BST solid solutions $(0.8<x<0.2)$ or $\mathrm{SrTiO}_{3}(x=0.0)$, (ii) all the powders are well crystallized and (iii) carbonate or other parasite phases are not detected. The zoom in the $29^{\circ}-35^{\circ} 2 \theta$ range shows two effects: first, the shift of the peaks toward high angle due to a decrease of the unit cell parameter with the strontium content, and second, a progressive increase of the line-width with the strontium content indicating the crystallization of smaller coherent domains. The coherent domain size $\left(D_{\mathrm{XRD}}\right)$ is also reported in this figure.

It is worth mentioning that FTIR has been recognized as one of the most sensitive techniques for carbonate identification [27]. The purity of the powders was confirmed by Fourier-transform infrared analysis. FTIR analysis of commercial BST powders frequently shows the presence of absorption bands around $1440 \mathrm{~cm}^{-1}$, due to $\mathrm{CO}_{3}^{2-}$ groups; such bands were not observed here whatever the composition of the powders. As an illustration, FTIR analysis of BST powder $(x=0.8)$ is reported in figure 2 . The following characteristics are systematically observed for the whole composition range: (i) the broad bands at 1355, 1545 and 


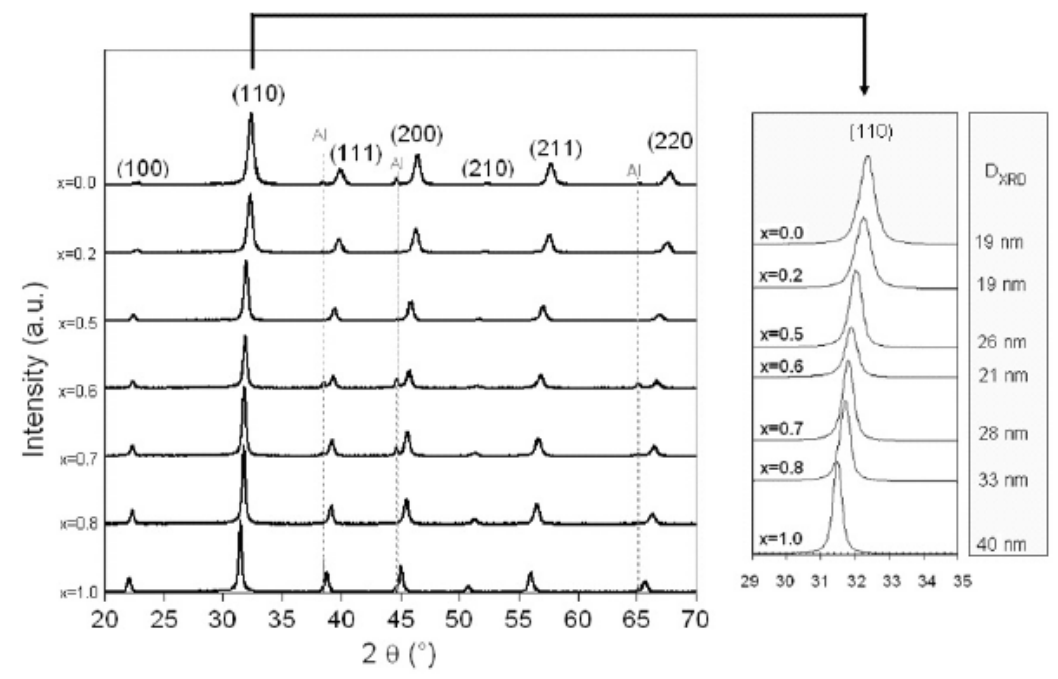

Figure 1. XRD pattern of $\mathrm{Ba}_{x} \mathrm{Sr}_{1-x} \mathrm{TiO}_{3}$ powders $\left(x=[\mathrm{Ba} / \mathrm{Ba}+\mathrm{Sr}]_{\text {prec }}\right)$ synthesized under supercritical conditions. Zoom in the $29^{\circ}-35^{\circ} 2 \theta$ range and mean crystallite size estimated by means of Scherrer's equation. The aluminium peaks correspond to the sample holders.

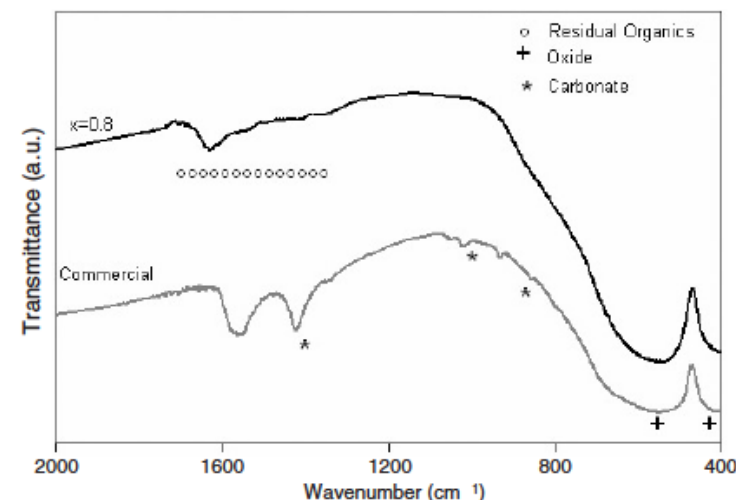

Figure 2. Typical FTIR analysis of BST nanopowder synthesized under supercritical conditions (in this case, $x=0.8$ ). The spectrum of a commercial BST nanopowder $(50 \mathrm{~nm})$ prepared using the sol-gel method is also shown.

$1636 \mathrm{~cm}^{-1}$ are attributed to residual organic groups (weight loss $<2 \%$ ); (ii) the characteristic bands of the carbonate group (1436, 1059 and $856 \mathrm{~cm}^{-1}$ ) are not observed, corroborating the absence of $\mathrm{BaCO}_{3}$ as impurity phase, and (iii) the broad bands near $\sim 540 \mathrm{~cm}^{-1}$ (Ti-O stretching vibrations) and below $500 \mathrm{~cm}^{-1}$ (corresponding to the $\mathrm{Ti}-\mathrm{O}$ bending vibrations) confirm the oxide crystallization. A spectrum obtained on a BST commercial nanopowder contaminated with barium carbonate is also displayed in figure 2 .

The variation of the powder lattice parameter as a function of the feed solution composition and the values reported by JCPDS standards are reported in figure 3. As shown in this figure, the measured lattice parameters match well the reported JCPDS values over the entire compositional range. The linear relationships followed allow the use of the Vegard's law to estimate the powder composition $\left(x=[\mathrm{Ba} / \mathrm{Ba}+\mathrm{Sr}]_{\text {powd }}\right)$ from calculated XRD lattice parameters. The best-fit line of data leads to a Vegard's law with $a=3.9030+0.1049 x\left(R^{2}=\right.$ 0.9823 , experimental data) or $a=3.9011+0.1045 x\left(R^{2}=\right.$ 0.9832 , JCPDS standards), where $a$ is the lattice parameter,

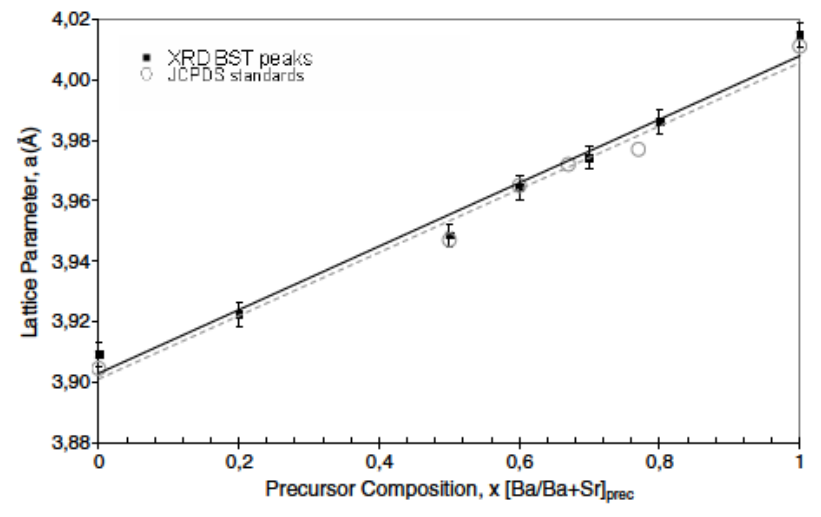

Figure 3. Lattice parameter of (口) the as-synthesized BST powders calculated from XRD patterns versus the corresponding feed solution compositions and (O) JCPDS values. This figure shows that a linear relationship is followed, allowing the use of Vegard's law for solid-solution composition estimation. (The solid line shows the linear regression fit of the XRD data. The dotted line shows the linear regression fit of the JCPDS standards.)

$x$ is the composition and $R^{2}$ is the square of the regression coefficient. Figure 4 shows the calculated mole fraction of barium in the as-synthesized powder $\left(x=[\mathrm{Ba} / \mathrm{Ba}+\mathrm{Sr}]_{\text {powd }}\right)$ as a function of the initial mole fraction of barium in the alkoxide feed solution $\left(x=[\mathrm{Ba} / \mathrm{Ba}+\mathrm{Sr}]_{\text {prec }}\right)$. The accuracy of the calculated compositions was verified by comparison with the corresponding compositions measured by ICP-AES.

Figure 4 gives last and conclusive evidence that an accurate control of the composition can be achieved using the continuous supercritical process. The as-prepared powder composition can be controlled from the composition of the feed solution over the whole composition range. Moreover, all the data points fit well on a straight $45^{\circ}$ line, indicating that the incorporation of strontium into the BST lattice is not preferential. This result is consistent with the work of Roeder et al, who measured minor deviations of BST powder composition from the initial solution composition 


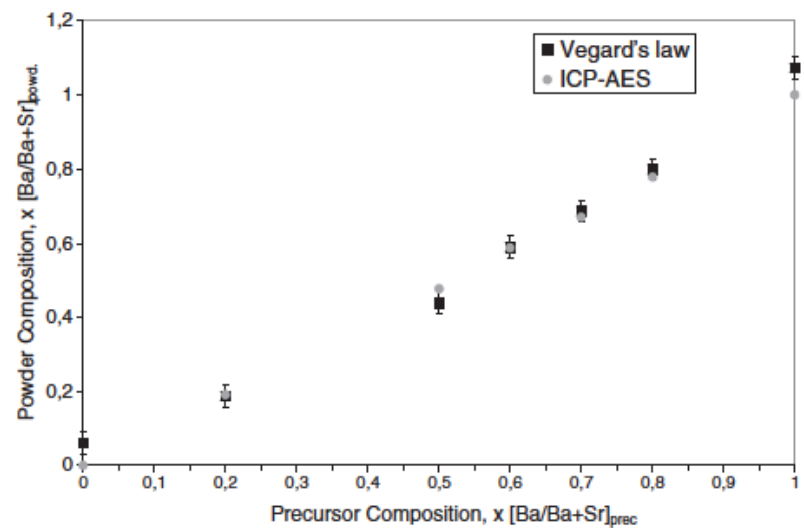

Figure 4. Estimated composition of the as-synthesized BST powders using Vegard's law and the ICP-AES technique versus the mole fraction of barium in the alkoxide feed solution used as precursor. The relative accuracy of the ICP-AES analysis is $2 \%$.

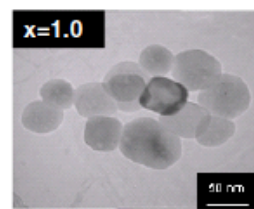

DTEM= $41 \mathrm{~nm}$

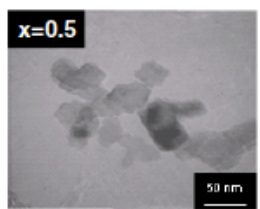

DTEM=25nm

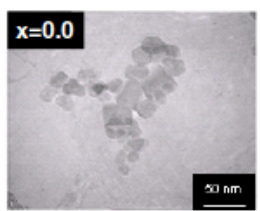

DTEM=19nm
Figure 5. TEM micrographs of $\mathrm{Ba}_{r} \mathrm{Sr}_{1-x} \mathrm{TiO}_{3}$ powders $\left(x=[\mathrm{Ba} / \mathrm{Ba}+\mathrm{Sr}]_{\text {powd }}\right)$ synthesized under supercritical conditions.

treated hydrothermally [22]. In contrast, Wei et al reported recently a preferential strontium incorporation over barium and attributed the Roeder's group results to an incomplete reaction of precursors [24]. Taking into account that our continuous process allows a full recovery of the introduced feed solution (precursor), some compositions were annealed in order to clarify this point. The same XRD pattern characteristics were observed in powders treated at $1325^{\circ} \mathrm{C} / 4 \mathrm{~h}$, indicating a total transformation of precursors and thereby the non-preferential incorporation of strontium over barium.

TEM images in figure 5 show that the prepared powders are formed by the aggregation of irregular-shaped nanoparticles with a diameter $\left(D_{\mathrm{TEM}}\right)$ of $41 \pm 13 \mathrm{~nm}\left(\mathrm{BaTiO}_{3}\right)$, $25 \pm 6 \mathrm{~nm}(x=0.5)$ or $19 \pm 5 \mathrm{~nm}$ (pure $\left.\mathrm{SrTiO}_{3}\right)$. The particle size obtained from TEM closely and consistently agreed with primary particles calculated from XRD, indicating that the as-synthesized nanoparticles are mostly monocrystalline and not aggregates of nanosized subunits as observed in many studies. This dependence of the BST particle size on the composition has already been reported in the literature (50 $80 \mathrm{~nm}$ in $\mathrm{SrTiO}_{3}$ compared to $100-150 \mathrm{~nm}$ in $\mathrm{BaTiO}_{3}$ ) [22, 24]. The finest particle size obtained in this work could result from the short residence times involved in our continuous method (near two minutes) compared with those applied in classical hydrothermal closed reactors (typically several hours). The standard deviation of the mean particle size remains elevated.

\subsection{Sintering and dielectric characterization}

The nanopowders were sintered in order to check the dielectric properties of the as-synthesized $\mathrm{Ba}_{x} \mathrm{Sr}_{1-x} \mathrm{TiO}_{3}$ compositions.
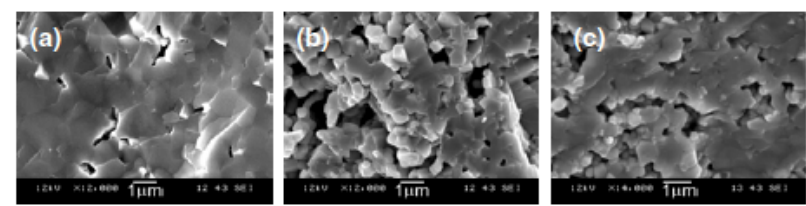

Figure 6. (a)-(c) SEM micrographs of some fracture surfaces of $\mathrm{Ba}_{x} \mathrm{Sr}_{1-x} \mathrm{TiO}_{3}$ ceramics sintered at $1325^{\circ} \mathrm{C}\left(x=[\mathrm{Ba} / \mathrm{Ba}+\mathrm{Sr}]_{\text {prec }}\right.$ (a) $x=0.0$, (b) $x=0.2$, (c) $x=0.7$ ).

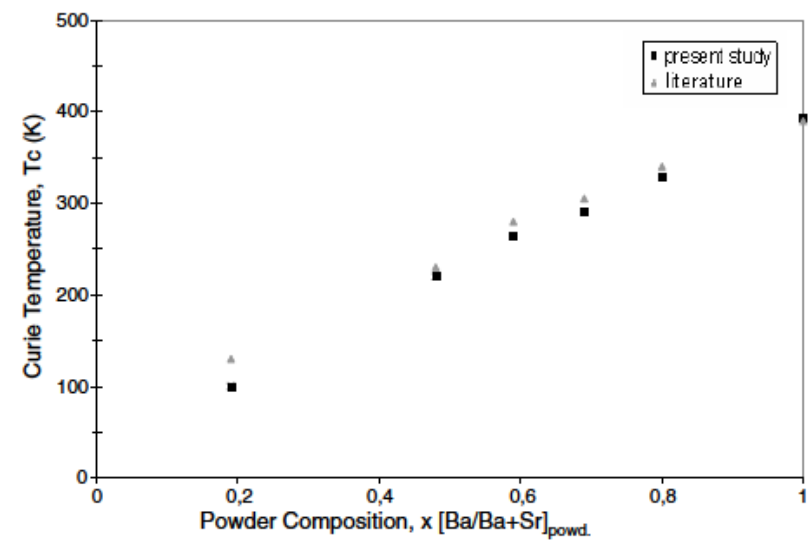

Figure 7. Curie temperature as a function of the powder composition in $\mathrm{Ba}_{\mathrm{r}} \mathrm{Sr}_{1-x} \mathrm{TiO}_{3}$ ceramics sintered at $1325^{\circ} \mathrm{C}$. $\mathbf{\square}$, values obtained in the present study; $\mathbf{\Lambda}$, average values from literature.

The aim in the present study is not the optimization of the sintering as a function of the composition but the determination of the Curie temperature $\left(T_{\mathrm{c}}\right)$ as an intrinsic parameter independent of the density of the ceramic [28]. The values of the relative densities of the compacts sintered at $1325^{\circ} \mathrm{C}$ are in the range $80-90 \%$ as a function of the ceramic compositions. SEM analysis has allowed the determination of the final grain size of as-sintered ceramics.

Figure 6 shows the ceramic microstructure obtained for three selected compositions. The best densification is obtained in the case of $\mathrm{SrTiO}_{3}$, which is characterized by the smallest initial grain size $(19 \mathrm{~nm})$. This behaviour is consistent with the higher reactivity of fine particles during sintering. The determination of the final grain size in the as-sintered ceramics is of main importance to rule out the contribution of a size effect to the measurement of $T_{\mathrm{c}}$. As for the three selected ceramics displayed in figure 6 , the average grain size value is well above the critical value reported in the literature for all the studied compositions [29].

The Curie temperature, obtained from the thermal variation of $\varepsilon_{\mathrm{r}}^{\prime}$ as a function of the calculated $[\mathrm{Ba} / \mathrm{Ba}+\mathrm{Sr}]_{\text {powd }}$ composition is reported in figure 7. As expected, the transition temperature decreases on increasing the strontium content. Note that a very good agreement is obtained with the values reported in the literature. Such an agreement supports the control of solid solution compositions achieved by our process. Only an average of the values reported in the literature is given here, considering the spreading of the results already reported $[15,26,28,30,31]$. Such a disparity is associated with the different synthesis processes (solid state, sol-gel, hydrothermal etc) used and then underlines 


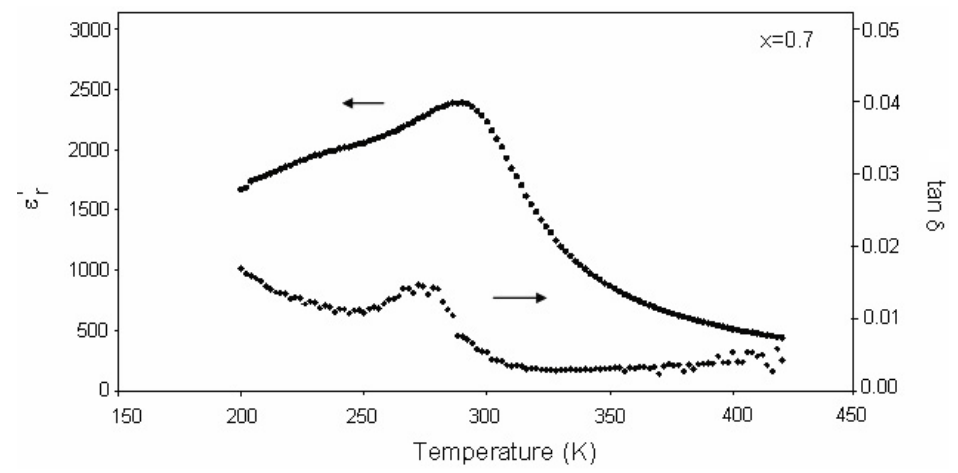

Figure 8. Dielectric permittivity and losses versus temperature measured at $1 \mathrm{kHz}$ on $\mathrm{Ba}_{0.7} \mathrm{Sr}_{0.3} \mathrm{TiO}_{3}$ powder sintered at $1325^{\circ} \mathrm{C}$.

the influence of parameters such as the chemistry defects (bulk hydroxyl groups, chemical composition) [5] on the ferroelectric behaviour.

Well crystallized and pure ferroelectric nanopowders with adjustable compositions can thus be obtained in one step using the continuous supercritical process described here. Some tedious steps found in other methods (sol-gel, precipitation, hydrothermal, mechanosynthesis, ...), such as washing, filtering, drying or calcining, are eliminated. In addition, except in the case of investigations using the solidstate route of synthesis, most of the studies in the literature report the dielectric behaviour of only one defined composition in the BST system. To our knowledge, this is the first time that the whole BST solid solution has been synthesized using the same wet synthesis method and fully characterized from a dielectric point of view.

The continuous supercritical approach presented here is relevant to control also the initial grain size of the powder as a function of the composition and then to drive the sintering kinetics. As a result, a tuning of dielectric permittivity, Curie temperature and dielectric losses would be possible, considering also the size effects in such ferroelectric compounds. Promising characteristics, in terms of Curie temperature and dielectric loss values, are obtained for the ceramic corresponding to the composition $\mathrm{Ba}_{0.7} \mathrm{Sr}_{0.3} \mathrm{TiO}_{3}$ (figure 8). The maximum of the permittivity is close to the room temperature and the corresponding dielectric losses are well below 1\%. An optimization of the sintering, in terms of both grain size and porosity control, is under investigation.

\section{Conclusion}

Well crystallized $\mathrm{Ba}_{x} \mathrm{Sr}_{1-x} \mathrm{TiO}_{3}$ (BST) nanopowders have been synthesized under supercritical conditions through a singlestep continuous synthesis over the entire range of composition, in the temperature range of $150-380^{\circ} \mathrm{C}$ at $26 \mathrm{MPa}$. This singlestep process avoids the long and tedious steps associated with other synthesis methods, such as washing, filtering, drying or calcining. Neither carbonate nor other secondary phases were produced, and in any case only single-phase solid solutions were synthesized. The use of alkoxides as precursors allowed the synthesis of BST solid solutions of controlled composition. The preferred incorporation of strontium already reported in hydrothermally synthesized BST powders and the formation of biphasic solid solutions were not observed here. The mean particle size of monocrystalline nanoparticles was found to be $\sim 20 \mathrm{~nm}$ in the case of Sr-rich powders $\left(\mathrm{SrTiO}_{3}\right)$ and $\sim 40 \mathrm{~nm}$ in the case of Ba-rich $\left(\mathrm{BaTiO}_{3}\right)$ powders. The ferroelectric transition temperature varied from $\sim 100$ to $390 \mathrm{~K}$, suggesting that an accurate adjustment of the ferroelectric properties of the as-synthesized powders is then possible. The composition $\mathrm{Ba}_{0.7} \mathrm{Sr}_{0.3} \mathrm{TiO}_{3}$ appears to be a promising material considering its dielectric characteristics: transition temperature $T_{\mathrm{c}}$ close to room temperature, maximum of permittivity close to 2500 and room temperature dielectric losses $<1 \%$.

\section{Acknowledgments}

This work was supported by the French National Center for Scientific Research (CNRS), the European Network of Excellence FAME, the European Community 'INTERREG III b-Arc Atlantique' Program and the 'Conseil Régional d'Aquitaine'.

\section{References}

[1] Yoon D and Lee B 2002 J. Ceram. Processing Res. 241

[2] Hu M, Miller G, Payzant E and Rawn C J 2000 Mater. Sci. 352927

[3] Bruno S and Swanson D 1993 J. Am. Ceram. Soc. 761233

[4] Young D and Lee B 2002 J. Ceram. Processing Res. 341

[5] Shi E, Xia C, Zhong W, Wang B and Feng C 1997 J. Am. Ceram. Soc. 801567

[6] Li X and Shih W 1997 J. Am. Ceram. Soc. 802844

[7] Lemanov V, Smirnova E, Syrnikov P and Tarakanov E 1996 Phys. Rev. B 543151

[8] Tiwari V, Singh N and Pandey D 1995 J. Phys.: Condens. Matter 71441

[9] Alexandru H, Berbecaru C, Ioachim A, Toacsen M, Banciu M, Nedelcu L and Ghetu D 2004 Mater. Sci. Eng. B 109152

[10] Chiu M, Cheng C, Wu W and Shieu F 2005 J. Electrochem. Soc. 152 F66

[11] Gersten B, Lencka M and Riman R 2004 J. Am. Ceram. Soc. 87 2025

[12] Wechsler B and Kirby K 1992 J. Am. Ceram. Soc. 75981

[13] Kao C and Wang W 1999 Appl. Organomet. Chem. 13383

[14] Fu C, Yang C, Chen H, Wang Y and Hu L 2005 Mater. Sci. Eng. B 119185

[15] Shen C, Lieu Q F and Lieu Q 2004 Mater. Lett. 582302

[16] Deshpande S, Khollam Y, Bhoraskar S, Date S, Sainkar S and Potdar H 2005 Mater. Lett. 59293 
[17] Yang X, Yao X and Zhang L 2004 Ceram. Int. 301525

[18] Chen X, Lu W, Zhu W, Lim S and Akbar S 2003 Surf. Coat. Technol. 167203

[19] Khollam Y, Deshpande S, Potdar H, Bhoraskar S, Sainkar S and Date S 2005 Mater. Charact. 5463

[20] Qi J, Wang Y, Chen W, Li L and Chan H 2005 J. Solid State Chem. 178279

[21] Selvam I and Kumar V 2002 Mater. Lett. 561089

[22] Roeder R and Slamovich E 1999 J. Am. Ceram. Soc. 821665

[23] Pinceloup P, Courtois P C, Leriche A and Thierry B 1999 J. Am. Ceram. Soc. 823049

[24] Wei X and Padture N 2004 Ceram. Process. Res. 5175
[25] Hungria T, Alguero M, Hungria A and Castro A 2005 Chem. Mater. 176205

[26] Reverón H, Elissalde C, Aymonier C, Bidault O, Maglione M and Cansell F 2005 J. Nanosci. Nanotechnol. 5174

[27] Lopez M C B, Fourlaris G, Rand B and Riley F L 1999 J. Am. Ceram. Soc. 821777

[28] Elissalde C, Reverón H, Aymonier C, Michau D, Cansell F and Maglione M 2005 Nanotechnology 16797

[29] Zhang L, Zhong W L, Wang Y G and Wang C L 1999 Appl. Phys. 32546

[30] Mitsui T and Landolt- B 1969 Ferroelectric and Antiferroelecric Substances vol 3 (Berlin: Springer)

[31] Liou J W and Chiou B S 1997 J. Am. Ceram. Soc. 803093 